\title{
Risk of Obstructive Sleep Apnea Assessment Among Patients With Type 2 Diabetes in Taif, Saudi Arabia
}

\author{
Reem Mohammed Noor Kalakattawi ${ }^{a}$, Afnan Mohammed Noor Kalakattawi ${ }^{b}$, Faisal Adel Alsuqatia \\ Sultanh Abdullah Alzhrania , Abdulmohsen Hamad Alhamyania , Abdulaziz Hamad Alhamyania, \\ Abrar Abdullah Al-Ghamdia , Ibtesam Mohammad Alosaimia , Salwa Ibrahim Abbas ${ }^{\mathrm{a}}$, \\ Lojain AbdulAziz Al-Shehria , Abdulrahman Ahmad Alzahrania, c
}

\begin{abstract}
Background: Obstructive sleep apnea (OSA) is a common condition in middle-aged persons worldwide. The major factor risk of this disease is obesity.

Methods: A cross-sectional study was performed at King AbdulAziz Specialist Hospital. A STOP-BANG questionnaire formed of eight questions was used to assess the risk of OSA among type 2 diabetic patients. The scoring scale is categorized into three groups: low $(0-2)$, intermediate $(3-4)$ and high $(5-8)$, respectively. By this study, we aimed to assess the risk of OSA among diabetes patients in Taif city.

Results: Of the patients, $57.9 \%$ had mild risk, $26.9 \%$ had moderate risk and $15.2 \%$ had severe risk for OSA. There was a moderate positive relationship between age and STOP-BANG score. There was no significant correlation between the score and last fasting blood sugar and HbA1c's level, with P values of 0.554 and 0.335 , respectively. There was a significant relationship between the type of treatment and the risk of developing OSA $(\mathrm{P}<0.001)$. Percentage of patients with severe risk was significantly higher in those taking both insulin and oral drugs than those taking insulin alone or oral drugs alone.
\end{abstract}

Conclusions: The OSA risk and prevalence is much higher in diabetics than in general population, with the risk increasing with age. The risk is higher in diabetic patients who are receiving both oral hypoglycemic drugs and insulin. The screening of OSA among diabetic patients is necessary to identify those at severe risk and manage this problem, which may remain undiagnosed in many patients.

Keywords: Obstructive sleep apnea; Diabetes; Saudi Arabia

Manuscript submitted September 7, 2017, accepted September 20, 2017

${ }^{a}$ College of Medicine, Taif University, Taif, Saudi Arabia

${ }^{b}$ College of Pharmacy, Taif University, Taif, Saudi Arabia

${ }^{\mathrm{c}}$ Corresponding Author: Abdulrahman Ahmad Alzahrani, College of Medicine, Taif University, Taif, Saudi Arabia. Email: aakz1415@gmail.com

doi: https://doi.org/10.14740/jocmr3189w

\section{Introduction}

Obstructive sleep apnea (OSA) is a repetitive episode of partial and complete airway obstructions during sleep. This disorder can be caused by common type of sleep disorders and this condition is associated with oxyhemoglobin desaturations [1, $2]$. The prevalence of OSA increases with aging. In men and women between 30 and 60 years old, the prevalence is $24 \%$ in men and $9 \%$ in women. OSA is common in both developing and developed countries and its prevalence has increased in the last two decades [3]. Most studies reported a 1.5- to three-fold higher prevalence of OSA in men [4]. The OSA has a number of risk factors, and the most important is obesity reflected by body mass index (BMI), neck circumference and waist to hip ratio $[5,6]$.

Other risk factors have been reported in the literature as aging, male gender, genetic predisposition, smoking, alcohol drinking and craniofacial anomalies [7, 8]. Cross-sectional studies indicate an association between OSA and certain medical conditions like type 2 diabetes mellitus, hypertension, heart failure, coronary heart disease and polycystic ovary syndrome [9-11]. OSA could be novel risk factor of type 2 diabetes or vice versa [12]. The glucose control in diabetics with OSA is poor and the severity of OSA is directly related to hemoglobin A1c values [13]. Studies reported a significant association between insulin resistance and sleep apnea in general population independently of any confounder especially obesity [14-16].

In a study conducted to test the effect of OSA treatment in diabetic patients, the authors found that insulin sensitivity enhanced after using of continuous positive airway pressure after two nights of treatment, and this was obvious in patients with BMI less than $30 \mathrm{~kg} / \mathrm{m}^{2}$ [17].

\section{Methodology}

\section{Objective}

We aimed to assess the risk of OSA among diabetic patients hospitalized from June to August 2017 at King Abdul-Aziz 
Table 1. The STOP-BANG Questionnaire

\begin{tabular}{|c|c|c|}
\hline & Yes* & No* \\
\hline \multicolumn{3}{|l|}{ STOP } \\
\hline Do you snore loudly (louder than talking or loud enough to be heard through closed doors)? & 1 & 0 \\
\hline Has anyone observed you stop breathing during your sleep? & 1 & 0 \\
\hline Do you have or are you being treated for high blood pressure? & 1 & 0 \\
\hline \multicolumn{3}{|l|}{ BANG } \\
\hline BMI more than $35 \mathrm{~kg} / \mathrm{m}^{2} ?$ & 1 & 0 \\
\hline Age over 50 years old? & 1 & 0 \\
\hline Neck circumference $>16$ inches $(40 \mathrm{~cm}) ?$ & 1 & 0 \\
\hline Gender : male? & 1 & 0 \\
\hline Total of scores & Out of & \\
\hline
\end{tabular}

$* 1,0=$ scores.

Specialist Hospital in Taif city, Saudi Arabia.

\section{Study design}

This study was a cross-sectional observational study.

\section{Study sample}

Inclusion criteria included patients hospitalized from June to August 2017 at King Abdul-Aziz Specialist Hospital in Taif city and diagnosed with type 2 diabetes mellitus. Exclusion criteria included the patients with type 1 diabetes or patients who did not have type 2 .

\section{Data collection}

Data were collected using the STOP-BANG sleep apnea screening questionnaire [18]. The questionnaire includes eight dichotomous questions that offer an easy method to assess the risk of OSA (Table 1). The scoring scale is categorized into three groups: low (0 - 2), intermediate $(3-4)$ and high (5 - 8), respectively. The answers were yes $(=1)$ and no $(=0)$ and the total score was 8 .

Other collected variables were other co-morbidities such as hypertension, coronary heart disease, heart failures, stroke or others. Also, oral medication or insulin injection, HbA1c and last fasting blood sugar (FBS) were collected.

Table 2. Gender Distribution in Diabetic Patients Hospitalized From June to August 2017 at King Abdul-Aziz Specialist Hospital $(n=197)$

\begin{tabular}{lll}
\hline Gender & n & \% \\
\hline Male & 87 & 44.2 \\
Female & 110 & 55.8 \\
\hline
\end{tabular}

\section{Statistical analysis}

To describe qualitative variables, frequency and percentage were used. The mean, median and standard deviation were used to describe quantitative variables.

To test the relationship between the score and quantitative variables, Spearman's correlation was used. To analyze the association between the level of OSA's risk and the type of treatment of diabetes, Chi-square test was used. The significant level of $\mathrm{P}$ was fixed at 0.05 .

\section{Results}

A total of 197 patients participated in our study, 55.8\% of them were females and $44.2 \%$ were males (Table 2 ). The mean age of the participants was 56.1 years and the standard deviation was 15.5 years. The minimum age was 12 years and the maximum was 93 years. Among our patients, 35\% had hyperten-

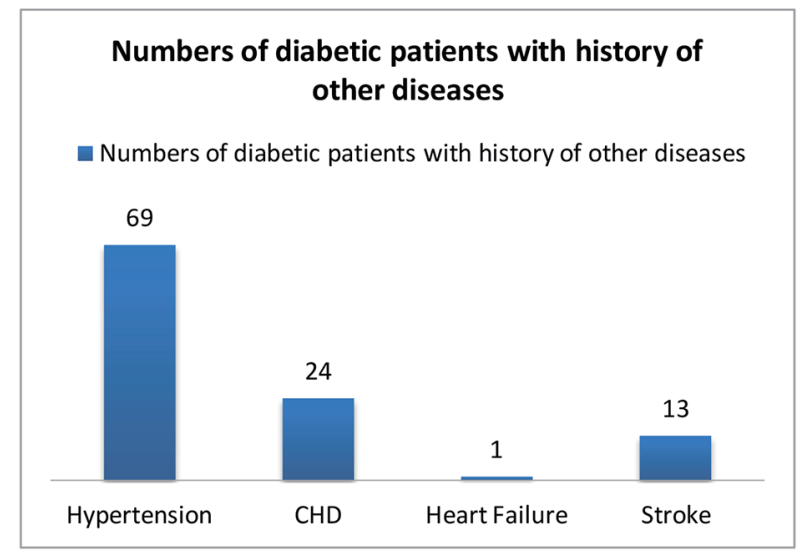

Figure 1. Numbers of diabetic patients with history of other diseases, hospitalized from June to August 2017 at King Abdul-Aziz Specialist Hospital $(n=197)$. 


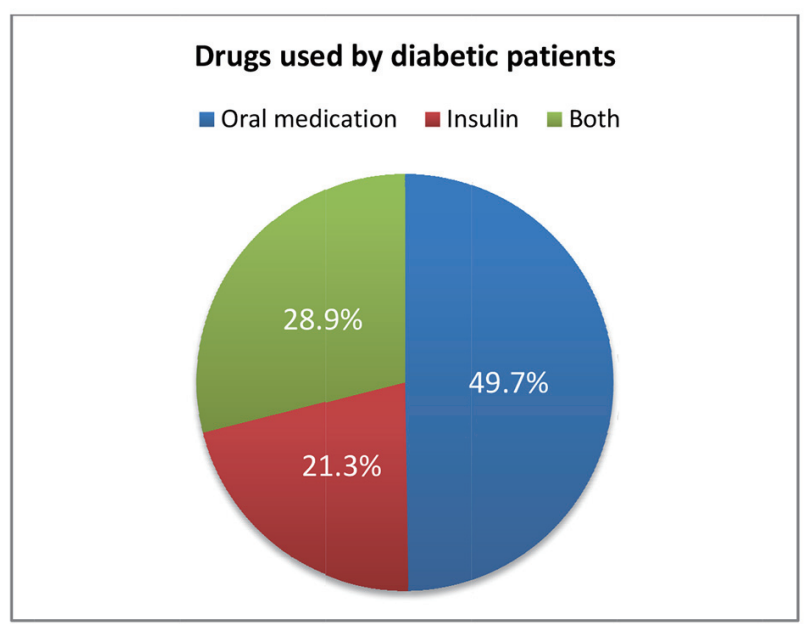

Figure 2. Drugs used by diabetic patients hospitalized from June to August 2017 at King Abdul-Aziz Specialist Hospital $(n=197)$.

sion, $12.2 \%$ had history of coronary heart disease and $6.6 \%$ had history of stroke. Only one patient had heart failure (Fig. 1). As regards diabetes treatment, $49.7 \%$ of the patients used oral hypoglycemic drugs, while $21.3 \%$ used insulin, and $28.9 \%$ of the patients used both insulin and oral hypoglycemic drugs (Fig. 2). Most of the patients participating in the study (166) were able to remember their last FBS reading, where the mean reading was $189.7 \mathrm{mmol} / \mathrm{L}$ and the standard deviation was 75.8 $\mathrm{mmol} / \mathrm{L}$. For the $\mathrm{HbA} 1 \mathrm{c}, 166$ patients mentioned their reading with the mean of $8.6 \%$ and the standard deviation of $2 \%$.

The score of STOP-BANG questionnaire was calculated for all the patients and the mean was 2.6, the standard deviation was 1.7 and the median was 2 (Table 3). Patients' risk was calculated based on the score of STOP-BANG questionnaire, and the result was that $57.9 \%$ of the patients had mild risk, $26.9 \%$ had moderate risk and $15.2 \%$ had severe risk of OSA (Fig. 3).

Spearman's correlation was calculated for the relationship between the score and the age which was significant with $\mathrm{P}$ value of $<0.001$, and the correlation coefficient was 0.35 . Spearman's correlation was also calculated for the FBS and the HbA1c, but it was non-significant with $\mathrm{P}$ values of 0.554 and 0.335 , respectively. Chi-square test was performed to test for the presence of relationship between the type of treatment and the risk severity of developing OSA, which was significant with $P$ value of $<0.001$. Percentage of patients with severe risk was higher in those taking both insulin and oral drugs than in those taking insulin alone or oral drugs alone (Fig. 4).

\section{Discussion}

A total of 197 diabetic patients participated in our study aiming

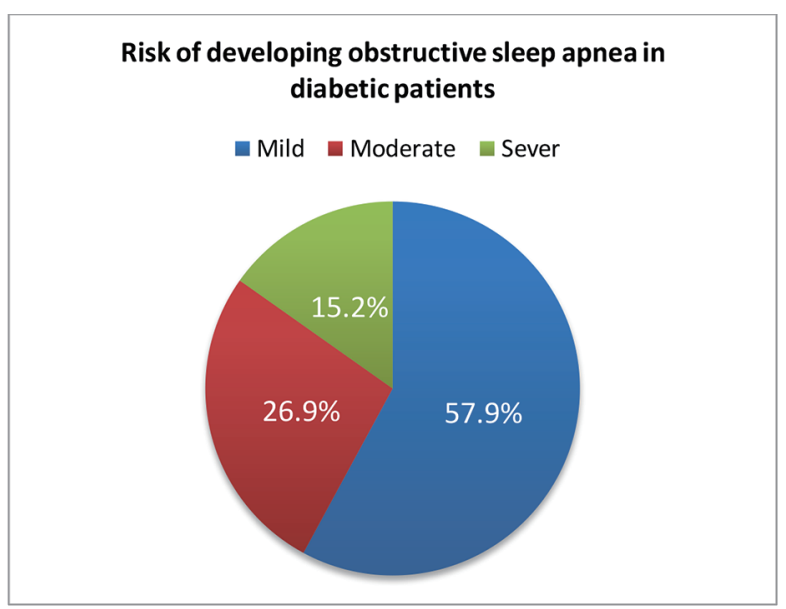

Figure 3. Risk of developing obstructive sleep apnea in diabetic patients hospitalized from June to August 2017 at King Abdul-Aziz Specialist Hospital $(n=197)$.

at assessing the risk of OSA in the diabetic patients in Taif city. The measurement tool used in this study was the STOP-BANG questionnaire. The score of STOP-BANG questionnaire was calculated for all the patients, the mean was 2.6 and the standard deviation was 1.7. According to the scores of the patients, $57.9 \%$ of patients had mild risk, $26.9 \%$ had moderate risk and $15.2 \%$ had severe risk for OSA. A significant correlation was found between the score and the age and the correlation coefficient was 0.35 , meaning that there is a moderate positive relationship between age and the score. There was no significant correlation between the score and FBS's level and between the score and the HbA1c's value.

The presence of relationship between the type of the treatment of the diabetes and the risk severity of developing OSA was tested and it was significant with $\mathrm{P}$ value of $<0.001$. Percentage of patients with severe risk was higher in those taking both insulin and oral drugs than those taking insulin alone or oral drugs alone.

The results of this study can be compared to those of a study published in 2006 studying the prevalence of OSA in men with type 2 diabetes [19].

The authors found that $57 \%$ were scored as "high" and $39 \%$ as "low" risk for OSA; $4 \%$ were already known to have OSA. The method used in this study is a questionnaire different from the STOP-BANG questionnaire. There was no significant difference in HbA1c levels between the "high" and "low" risk groups, which is the same result we reached in our study.

Another study focused on OSA among obese patients with type 2 diabetes. It showed that over $86 \%$ of participants had OSA with an apnea-hypopnea index (AHI) $\geq 5$ events/h. The mean AHI was $20.5 \pm 16.8$ events/h. A total of $30.5 \%$ of the participants had moderate OSA $(15 \leq \mathrm{AHI}<30)$, and $22.6 \%$

Table 3. STOP-BANG Questionnaire Score in Diabetic Patients Hospitalized From June to August 2017 at King Abdul-Aziz Specialist Hospital $(n=197)$

\begin{tabular}{lllllll} 
& n & Minimum & Maximum & Median & Mean & Standard deviation \\
\hline Total scores & 197 & 0 & 7 & 2 & 2.56 & 1.724 \\
\hline
\end{tabular}




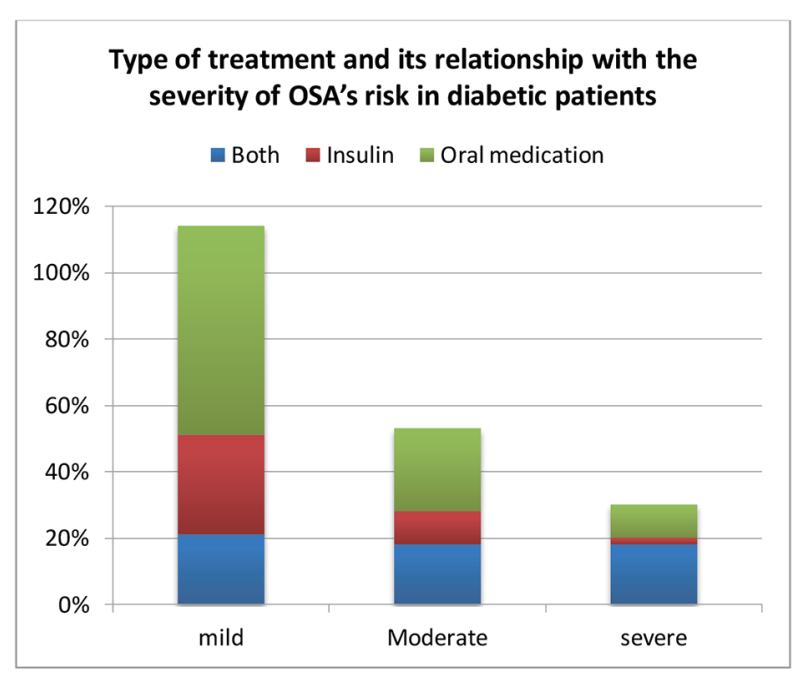

Figure 4. Type of treatment and its relationship with the severity of OSA's risk in diabetic patients hospitalized from June to August 2017 at King Abdul-Aziz Specialist Hospital $(n=197)$.

had severe OSA (AHI $\geq 30)$ [20].

In a study conducted to test the relationship between sleepdisordered breathing and insulin resistance, authors found that sleep-disordered breathing parameters (AHI and minimum oxygen saturation) were independent determinants of insulin resistance [21].

A population-based study performed in 1,387 participants of the Wisconsin Sleep Cohort found a significant association between sleep apnea and type 2 diabetes, and this relationship was independent from other risk factors [22].

\section{Conclusion}

In conclusion, the OSA risk and prevalence is much higher in diabetics than in general population, with the risk increasing with age. The risk is higher in diabetic patients who received both oral hypoglycemic drugs and insulin. These results suggest that the screening of OSA among diabetic patients is necessary to identify those at severe risk and manage this problem, which may remain undiagnosed in many patients.

\section{Source(s) of Support}

None.

\section{Conflict of Interest}

None.

\section{References}

1. Lam JC, Sharma SK, Lam B. Obstructive sleep apnoea: definitions, epidemiology \& natural history. Indian J Med Res. 2010;131:165-170.

2. Patil SP, Schneider H, Schwartz AR, Smith PL. Adult obstructive sleep apnea: pathophysiology and diagnosis. Chest. 2007;132(1):325-337.

3. Garvey JF, Pengo MF, Drakatos P, Kent BD. Epidemiological aspects of obstructive sleep apnea. J Thorac Dis. 2015;7(5):920-929.

4. Punjabi NM. The epidemiology of adult obstructive sleep apnea. Proc Am Thorac Soc. 2008;5(2):136-143.

5. Tishler PV, Larkin EK, Schluchter MD, Redline S. Incidence of sleep-disordered breathing in an urban adult population: the relative importance of risk factors in the development of sleep-disordered breathing. JAMA. 2003;289(17):2230-2237.

6. Al Lawati NM, Patel SR, Ayas NT. Epidemiology, risk factors, and consequences of obstructive sleep apnea and short sleep duration. Prog Cardiovasc Dis. 2009;51(4):285-293.

7. Young T, Skatrud J, Peppard PE. Risk factors for obstructive sleep apnea in adults. JAMA. 2004;291(16):20132016.

8. Franklin KA, Lindberg E. Obstructive sleep apnea is a common disorder in the population-a review on the epidemiology of sleep apnea. J Thorac Dis. 2015;7(8):13111322.

9. Foster G, Kuna ST, Sanders M, et al. Sleep apnea in obese adults with type 2 diabetes: baseline results from the Sleep AHEAD study. Sleep. 2005;28:A606.

10. Fogel RB, Malhotra A, Pillar G, Pittman SD, Dunaif A, White DP. Increased prevalence of obstructive sleep apnea syndrome in obese women with polycystic ovary syndrome. J Clin Endocrinol Metab. 2001;86(3):1175-1180.

11. Logan AG, Perlikowski SM, Mente A, Tisler A, Tkacova R, Niroumand M, Leung RS, et al. High prevalence of unrecognized sleep apnoea in drug-resistant hypertension. $\mathbf{J}$ Hypertens. 2001;19(12):2271-2277.

12. Pamidi S, Tasali E. Obstructive sleep apnea and type 2 diabetes: is there a link? Front Neurol. 2012;3:126.

13. Aronsohn RS, Whitmore H, Van Cauter E, Tasali E. Impact of untreated obstructive sleep apnea on glucose control in type 2 diabetes. Am J Respir Crit Care Med. 2010;181(5):507-513.

14. Punjabi NM, Shahar E, Redline S, Gottlieb DJ, Givelber R, Resnick HE, Sleep Heart Health Study I. Sleepdisordered breathing, glucose intolerance, and insulin resistance: the Sleep Heart Health Study. Am J Epidemiol. 2004;160(6):521-530.

15. Theorell-Haglow J, Berne C, Janson C, Lindberg E. Obstructive sleep apnoea is associated with decreased insulin sensitivity in females. Eur Respir J. 2008;31(5):10541060.

16. Punjabi NM, Beamer BA. Alterations in glucose disposal in sleep-disordered breathing. Am J Respir Crit Care Med. 2009;179(3):235-240.

17. Harsch IA, Schahin SP, Radespiel-Troger M, Weintz O, Jahreiss H, Fuchs FS, Wiest GH, et al. Continuous positive airway pressure treatment rapidly improves insulin sensitivity in patients with obstructive sleep apnea syn- 
drome. Am J Respir Crit Care Med. 2004;169(2):156162.

18. Chung F, Abdullah HR, Liao P. STOP-Bang Questionnaire: A Practical Approach to Screen for Obstructive Sleep Apnea. Chest. 2016;149(3):631-638.

19. West SD, Nicoll DJ, Stradling JR. Prevalence of obstructive sleep apnoea in men with type 2 diabetes. Thorax. 2006;61(11):945-950.

20. Foster GD, Sanders MH, Millman R, Zammit G, Borradaile KE, Newman AB, Wadden TA, et al. Obstructive sleep apnea among obese patients with type 2 diabetes. Diabetes Care. 2009;32(6):1017-1019.

21. Ip MS, Lam B, Ng MM, Lam WK, Tsang KW, Lam KS. Obstructive sleep apnea is independently associated with insulin resistance. Am J Respir Crit Care Med. 2002;165(5):670-676.

22. Reichmuth KJ, Austin D, Skatrud JB, Young T. Association of sleep apnea and type II diabetes: a population-based study. Am J Respir Crit Care Med. 2005;172(12):15901595. 